\title{
Observation of Distressed Conspecific as a Model of Emotional Trauma Generates Silent Synapses in the Prefrontal-Amygdala Pathway and Enhances Fear Learning, but Ketamine Abolishes those Effects
}

\author{
Wataru Ito', Alev Erisir ${ }^{2}$ and Alexei Morozov ${ }^{*, 1,3,4}$ \\ 'Virginia Tech Carilion Research Institute, Roanoke, VA, USA; '2Department of Psychology, University of Virginia, Charlottesville, VA, USA; \\ ${ }^{3}$ Department of Biomedical Engineering and Mechanics, School of Biomedical Engineering and Sciences, Virginia Tech, Blacksburg, VA, USA; \\ ${ }^{4}$ Department of Psychiatry and Behavioral Medicine, Virginia Tech Carilion School of Medicine, Roanoke, VA, USA
}

\begin{abstract}
Witnessing pain and distress in others can cause psychological trauma and increase odds of developing PTSD in the future, on exposure to another stressful event. However, the underlying synaptic process remains unknown. Here we report that mice exposed to a conspecific receiving electrical footshocks exhibited enhanced passive avoidance (PA) learning when trained $24 \mathrm{~h}$ after the exposure. The exposure activated neurons in the dorsomedial prefrontal cortex (dmPFC) and basolateral amygdala (BLA) and altered synaptic transmission from dmPFC to BLA. It increased amplitude, slowed decay of NMDA receptor-mediated currents, and generated silent synapses. Administration of sub-anesthetic ketamine immediately after the exposure prevented the enhancement of PA learning and silent synapse formation. These findings suggest that ketamine can prevent pathophysiological consequences of psychological trauma.

Neuropsychopharmacology (2015) 40, 2536-2545; doi:I0.1038/npp.2015.I00; published online I3 May 2015
\end{abstract}

\section{INTRODUCTION}

Purely psychological distress, without physical pain or physical discomfort, renders brain more vulnerable to a broad range of traumatic events, increasing chances of mental illness (Cougle et al, 2009; Resnick et al, 1995). In particular, exposure to the person(s) in pain and distress is recognized as a cause of psychological distress, which can produce fear learning (Olsson et al, 2007) and elicit traits of PTSD (Eriksson et al, 2001; Figley, 1995; Munroe, 1999). Such exposure, in contrast to physical pain, recruits the brain circuits for social cognition through multimodal sensory processing. The underlying mechanisms are of particular interest because they are relevant to mental illness and may drive the essentials of human nature-compassion and empathy.

Observational fear paradigms are models of psychological trauma in rodents, in which an observer animal is exposed to a conspecific in physical pain or distress, typically from electrical foot shocks or social defeat. Such exposures interrupt ongoing activities (Church, 1959), increase depression and anxiety-like behaviors (Warren et al, 2013), and elicit fear learning (Chen et al, 2009; Jeon et al, 2010;

*Correspondence: Dr A Morozov, Virginia Tech Carilion Research Institute, 2 Riverside Circle, Roanoke, VA 240 I6, USA, Tel: + I 540526 2021, Fax: + 540985 3373, E-mail: alexeim@vtc.vt.edu

Received 20 December 2014; revised 7 April 2015; accepted 8 April 2015; accepted article preview online 13 April 2015
Yusufishaq and Rosenkranz, 2013). Emotionally salient stimuli generally recruit the dorsomedial prefrontal cortex (dmPFC) and the basolateral amygdala (BLA), which have strong reciprocal projections (Hubner et al, 2014; McDonald, 1998) and are involved in fear learning (Gilmartin et al, 2014; Marek et al, 2013; Senn et al, 2014), including contextual learning during observational fear (Amano et al, 2010; Jeon et al, 2010). Fear learning increases oscillatory synchronization between the two structures (Lesting et al, 2011; Likhtik et al, 2014; Stujenske et al, 2014), the amplitude of which correlates with the strength of fear memory (Popa et al, 2010). On the other hand, synaptic inputs from the medial prefrontal cortex to BLA excitatory neurons become attenuated after fear extinction (Cho et al, 2013). These observations suggest that aversive experiences strengthen synaptic connections between $\mathrm{dmPFC}$ and BLA. Here we identified a potential synaptic substrate of such strengthening in a mouse model of psychological trauma and correlated it with subsequent enhancement of Pavlovian fear learning.

\section{MATERIALS AND METHODS}

\section{Animals}

129SvEv/C57BL/6N F1 hybrid male mice were produced from breeding trios of one C57BL/6N male and two $129 \mathrm{SvEv}$ females, weaned at p21, and housed two littermates per cage (polycarbonate, $189 \times 297 \times 128 \mathrm{~mm}$, filtered top, 
Allentown, NJ) at $69-70{ }^{\circ} \mathrm{F}, 62-68 \%$ humidity, with air exchanged 60 times per hour at the negative pressure mode, under 12:12 light/dark cycle (0700 to 1900 hours). Bedding was hardwood chips (Beta Chip, NEPCO, Warrensburg, NY). A TP roll $\left(1.5^{\prime \prime} \times 4.5^{\prime \prime}\right.$, Jonesville Paper Tube Corp, Jonesville, MI), a 2" $\times 2$ " nestlet, and a pinch of Enviro-Dri (PharmaServ, Framingham, MA) served as environmental enrichment. Food (Rodent NIH-07 open formula diet, Zeigler Bros, Gardners, PA) and water through a water bottle and a sipper (Sta-Pure Systems, Carnegie, PA) were provided ad libitum. To ameliorate stress and body weight loss at weaning, special diet (Jell-O based calorie supplement) was given at p21-p28 (4 g per animal per day). ChR2$\mathrm{AAV}$ virus was injected at p28 and experiments were performed at p60-p75, according to Virginia Tech IACUCapproved protocol.

\section{Behavior}

All tests were done during the light phase of the day cycle. All chambers were thoroughly cleaned and dried between sessions to minimize odor from subjects. Inside walls were wiped with paper towels containing water and then $70 \%$ ethanol. Rod floors and bottom trays were washed by running water.

Observational fear. Observational fear (OF) procedure (Jeon et al, 2010) was performed in a fear conditioning chamber (Med Associates, St Albans, VT), divided into two unequal compartments by a transparent Plexiglas wall with $7-\mathrm{mm}$ diameter holes, spaced at $2 \mathrm{~cm}$ interval (Figure $1 \mathrm{~b}$ ), to allow auditory and olfactory cues and whisker-to-whisker interaction. In the larger $26 \times 20 \times 26 \mathrm{~cm}$ compartment, a stainless-steel rod floor was covered with a white plastic sheet. In the smaller $26 \times 9 \times 26 \mathrm{~cm}$ compartment, the rod floor was exposed. Cagemates observer and demonstrator were placed, respectively, in the larger and the smaller compartments. After 5-min acclimation, 24 footshocks ( $1 \mathrm{~mA}, 2 \mathrm{~s}$, every $10 \mathrm{~s}$ ) were delivered to the demonstrator. The observer was returned to the home cage and housed alone. In the control procedure, demonstrators did not receive footshocks.

Passive avoidance. The one trial step-through paradigm (El-Ghundi et al, 2001) was employed using Gemini Avoidance System with mouse passive avoidance (PA) start boxes (San Diego Instruments, San Diego, CA). For training, a mouse was placed in the starting side of the chamber with a guillotine door closed, and lights turned off. After 60-s acclimation, room and cue lamps were turned on in the starting side, and the door was opened. Once mice entered the dark side, the door was closed and a $0.15 \mathrm{~mA} 1$-sec electrical footshock was delivered. Mice were returned to home cages $30 \mathrm{~s}$ after the door closure. One day later, the same procedure, but without footshock, was used for testing avoidance memory by measuring the latency to enter the dark side.

Immobilization stress. A mouse was placed in a $50 \mathrm{ml}$ Falcon tube with a $10 \mathrm{~mm}$ opening at the bottom for breathing, for $2 \mathrm{~h}$. Thereafter, mice were returned to home cages and housed alone.
Fear conditioning training. Animals were trained by three pairings of 30 -s tone $(8 \mathrm{kHz}, 85 \mathrm{~dB})$, co-terminated with an electrical footshock (0.5 mA, $0.5 \mathrm{~ms}$ ) (Ito et al, 2009), presented during a 420 -s session at pseudorandom intervals. Mice were returned to home cages and housed alone.

\section{Histology}

c-Fos immunoreactivity. Ninety min after the OF procedure, mice were anaesthetized with $2.5 \%$ avertin $(10 \mathrm{ml}$ per $\mathrm{kg}$ ) and transcardially perfused with $10 \mathrm{ml}$ of saline followed by $20 \mathrm{ml}$ of $4 \%$ paraformaldehyde (PFA) in $10 \mathrm{mM}$ phosphate buffer saline, $\mathrm{pH} 7.4$ (PBS). The brains were removed from skull, postfixed in PFA overnight and sliced into $75 \mu \mathrm{m}$ coronal sections using Vibratome (The Vibratome Company, St Louis, MO). Sections were washed in PBS for $15 \mathrm{~min}$, incubated for $1 \mathrm{~h}$ in PBST (0.2 \% Triton X-100 in PBS) containing $2 \%$ normal donkey serum (NDS), incubated overnight at $4{ }^{\circ} \mathrm{C}$ in PBST containing $2 \%$ NDS with goat anti c-Fos antibody $(1: 3000$, Santa-Cruz, Dallas, TX), washed three times in PBST, incubated for $2 \mathrm{~h}$ with biotinylated donkey anti-goat IgG (1:200), followed by antigen detection with VECTASTAIN Elite ABC Kit and DAB Peroxidase Substrate Kit (Vector Laboratories, Burlingame, CA). Bright field images were acquired using Stemi SV11 microscope (Zeiss, Thornwood, NY), ProgRes C10plus Camera, and PregRes CapturePro 2.8.8 software (GenOptik, Jena, Germany). C-Fos-positive nuclei were counted in the $1 \times 0.5 \mathrm{~mm}$ rectangular areas (Figure 1d) covering the prelimbic cortex and ventral part of the anterior cingulate cortex in two adjacent dmPFC slices within 1.54 to $1.7 \mathrm{~mm}$ from bregma. In BLA, c-Fos-positive nuclei were counted in two adjacent slices within -1.3 to $-1.5 \mathrm{~mm}$ from bregma. The counting was done blindly to treatment conditions.

\section{Surgery}

Viral injections. ChR2-AAV pseudo-type 1 virus at the titer of $10^{12}$ viral particles per $\mathrm{ml}$ was prepared by the University of North Carolina Gene Therapy Vector Core (Chapel Hill, NC) using Addgene plasmid 20071 (Petreanu et al, 2009), in which ChR2-Venus expression is driven by CAG promoter. P28 mice were anesthetized with Ketamine/ Xylazine/Acepromazine (100/20/3 mg/kg) injected intramuscularly after induction by $5 \%$ Isoflurane and placed in a stereotaxic apparatus (David Kopf, Tujunga, CA). After minimum craniotomy ( $0.5 \mathrm{~mm}$ diameter), preserving the dura mater, a heater-pulled glass pipette (shaft: $0.6 / 0.4 \mathrm{~mm}$ external/internal diameter, tip: $50 \mu \mathrm{m}$, Drummond, Broomall, PA) filled with the virus solution was slowly lowered to target brain areas.About $0.5 \mu \mathrm{l}$ of the solution were injected bilaterally, using a syringe pump connected to the pipette through plastic tubing filled with water, in $\mathrm{dmPFC}$ at $1.3 \mathrm{~mm}$ anterior, $0.4 \mathrm{~mm}$ lateral from bregma, and $1.3 \mathrm{~mm}$ ventral from brain surface or in the temporal association cortex $(\mathrm{TeA})$ at $2.8 \mathrm{~mm}$ posterior, $4.6 \mathrm{~mm}$ lateral from bregma, and $1.8 \mathrm{~mm}$ ventral from brain surface, as described (Morozov et al, 2011). For post-operation analgesia, ketoprofen (5 mg/ $\mathrm{kg}$ ) was administered subcutaneously. To prevent body weight loss caused by surgery, Jell-O-based calorie supplement was given for 1 week ( $4 \mathrm{~g}$ per animal per day). 


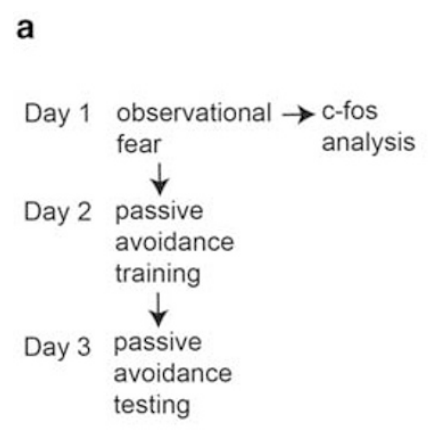

b
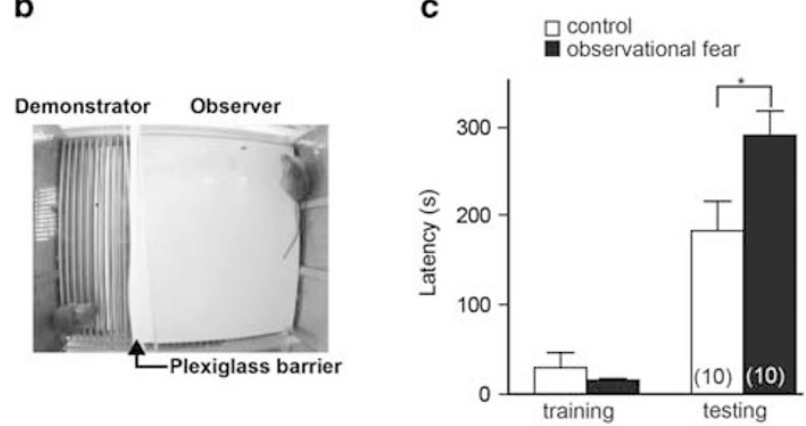

f
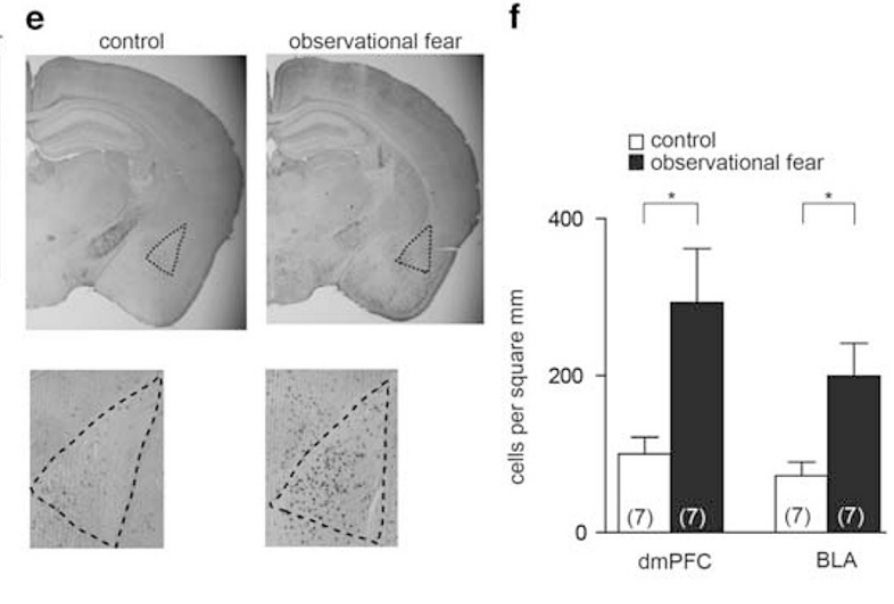

Figure I OF enhances PA learning and recruits dmPFC and BLA (a) Experiment timeline. (b) OF chamber. (c) Latencies to enter dark compartment during PA training and testing. ( $d$ and e) Representative c-Fos immunostaining of dmPFC (d) and BLA (e) slices from control and OF mice. Insets show magnified images of quantified areas. (f) Summary counts of c-Fos-positive cells per $\mathrm{mm}^{2}$. White and black represent, respectively, control and OF. Data are presented as mean \pm SEM. Number of animals are shown in parentheses. ${ }^{*} p<0.05$. BLA, basolateral amygdala; dmPFC, dorsomedial prefrontal cortex; OF, observational fear; $P A$, passive avoidance.

\section{Electrophysiology}

General. Amygdala slices, 300- $\mu \mathrm{m}$ thick, were prepared as described (Morozov et al, 2011) using ice cold partial sucrose artificial cerebrospinal fluid (ACSF) solution containing $\mathrm{NaCl} 80 \mathrm{mM}$, KCl $3.5 \mathrm{mM}, \mathrm{MgSO}_{4} 4.5 \mathrm{mM}, \mathrm{CaCl}_{2} 0.5 \mathrm{mM}$, $\mathrm{H}_{2} \mathrm{PO}_{4} 1.25 \mathrm{mM}, \mathrm{NaHCO}_{3} 25 \mathrm{mM}$, glucose $10 \mathrm{mM}$, and sucrose $90 \mathrm{mM}$ equilibrated with $95 \% \mathrm{O}_{2} / 5 \% \mathrm{CO}_{2}$ (Daw et al, 2009), incubated at $33^{\circ} \mathrm{C}$ for $30 \mathrm{~min}$ and stored in the same solution at room temperature for at least $45 \mathrm{~min}$ before recording. Recording chamber was superfused at $2 \mathrm{ml} / \mathrm{min}$ with ACSF equilibrated with $95 \% \mathrm{O}_{2} / 5 \% \mathrm{CO}_{2}$ and containing $\mathrm{NaCl} 119 \mathrm{mM}, \mathrm{KCl} 2.5 \mathrm{mM}, \mathrm{MgSO}_{4} 1 \mathrm{mM}, \mathrm{CaCl}_{2} 2.5 \mathrm{mM}$, $\mathrm{H}_{2} \mathrm{PO}_{4} 1.25 \mathrm{mM}, \mathrm{NaHCO}_{3} 26 \mathrm{mM}$, glucose $10 \mathrm{mM}$, and picrotoxin $100 \mu \mathrm{M}$ ( $\mathrm{pH}$ 7.4). Whole cell recordings were obtained at $30 \pm 1{ }^{\circ} \mathrm{C}$ with EPC-10 amplifier and Pulse v8.76 software (HEKA Elektronik, Lambreht/Pfaltz, Germany). Putative glutamatergic neurons in BLA were identified by their pyramidal morphology (McDonald, 1982) under Dodt gradient contrast optics (cusom made) at $850 \mathrm{~nm}$ LED illumination (Thorlabs, Newton, NJ) and were recorded using 2-4M pipette filled with Cs-methanesulfonate $120 \mathrm{mM}, \mathrm{NaCl} 5 \mathrm{mM}, \mathrm{MgCl}_{2} 1 \mathrm{mM}$, HEPES $10 \mathrm{mM}$ and EGTA $0.2 \mathrm{mM}$, ATP-Mg $2 \mathrm{mM}$, GTP-Na $0.1 \mathrm{mM}$, and QX314 $10 \mathrm{mM}, \mathrm{pH} 7.3$, osmolarity 285 osM. Membrane potentials were corrected by the junction potential of $12 \mathrm{mV}$. Series resistance (Rs) was $10-20 \mathrm{M} \Omega$ and monitored throughout experiments. Data were not included in the analysis if Rs changed more than $20 \%$. Light pulses ( $470 \mathrm{~nm}$, $1 \mathrm{~ms}$ ) were generated using an LED lamp (Thorlabs) and a custom LED driver based on MOSFET and were delivered through a $\times 40$ objective lens (Olympus, Center Valley, PA) at $0.3-2.5 \mathrm{~mW}$, calibrated by a photodiode power sensor (Thorlabs) at the tip of the lens.

AMPAR/NMDAR index. AMPAR currents were measured at the peak response in cells held at $-75 \mathrm{mV}$ membrane potential. NMDAR currents were determined at $50 \mathrm{~ms}$ after the peak in cells held at $+40 \mathrm{mV}$. Stimulus intensity was adjusted to keep the amplitude of AMPAR currents within the range of -50 to $-200 \mathrm{pA}$. AMPAR/NMDAR indices were determined from the averages of 10-25 excitatory postsynaptic currents (EPSCs).

AMPAR/NMDAR ratio. Mixed AMPAR and NMDAR currents were recorded in cells held at $+40 \mathrm{mV}$ membrane potential, which was followed by recording of NMDAR currents isolated in the presence of $20 \mu \mathrm{M}$ CNQX in the bath. Ten consecutive traces were used to obtain averages. The trace representing AMPAR current was obtained by subtracting the averaged trace for NMDAR current from the trace for AMPAR+NMDAR mixed current. The 
AMPAR/NMDAR ratio was calculated from the peak values of isolated AMPAR and NMDAR currents.

Reversal potentials were determined from the linear portion of the current-voltage plots obtained from recording of pharmacologically isolated AMPAR (in the presence of $100 \mu \mathrm{M}$ picrotoxin and $25 \mu \mathrm{M} \mathrm{APV}$ ) and NMDAR (in the presence of $100 \mu \mathrm{M}$ picrotoxin and $20 \mu \mathrm{M} \mathrm{CNQX).}$

Minimal-like AMPAR and NMDAR currents. Minimallike stimulation using a light spot of about $25 \mu \mathrm{m}$ diameter (Figure 3a) was obtained by placing a $400 \mu \mathrm{m}$ diaphragm (Edmund Optics, Barrington, NJ) at the position of a field diaphragm in a reflected illumination path (Olympus). Stimulation intensity was reduced to the threshold to generate alternating failures and responses of same latency and not exceeding $35 \mathrm{pA}$ in absolute value. AMPAR currents were recorded at $-75 \mathrm{mV}$ membrane potential in the presence of $100 \mu \mathrm{M}$ picrotoxin and $25 \mu \mathrm{M}$ APV. NMDAR currents were recorded at $+40 \mathrm{mV}$ in the presence of $100 \mu \mathrm{M}$ picrotoxin and $20 \mu \mathrm{M}$ CNQX. Successes (EPSCs) and failures were identified visually and traces contaminated by spontaneous activity were removed from the analysis. Mean peak responses were determined by averaging 10-25 EPSCs. To test for multi-synaptic responses, in a subset of neurons, AMPAR currents were elicited by paired-pulse stimulation, 50-75 repeats per cell. The potencies of the first response were also included in the comparisons shown on Figure 3d.

NMDAR current decay time. NMDAR currents of 50$300 \mathrm{pA}$ peak amplitude were evoked by widefield light stimulation. The decay time from 90 to $30 \%$ of the peak was determined.

Silent synapses. Two methods were employed for detecting silent synapses: the coefficient of variation (CV) analysis and minimal-like stimulation (Kullmann, 1994; Marie et al, 2005; Pan et al, 2009). CVs were determined for epochs of 25 consecutive trials separated by $10 \mathrm{~s}$. Sample variance (SV) was calculated for the amplitudes of EPSC or noise with sweeps obtained, respectively, with or without stimulation. The CVs were calculated using the formula: $\frac{\sqrt{\text { (SV[EPSC]-SV[noise] }}}{\text { EPSC mean }}$. The minimal-like stimulation using the $25-\mu \mathrm{m}$ diameter light spot was employed to compare failure rates of AMPAR EPSC recorded at $-75 \mathrm{mV}$ and mixed AMPAR/NMDAR EPSC recorded at $+40 \mathrm{mV}$. Stimulus intensity was adjusted to obtain success rate for AMPAR EPSC within the range of $30-70 \%$. No threshold or amplitude criteria of minimal stimulation were applied. Twenty-five to 100 traces were recorded at each membrane potential. Failures and responses at $-75 \mathrm{mV}\left(\mathrm{F}_{-75}\right)$ and at $+40 \mathrm{mV}\left(\mathrm{F}_{+40}\right)$ were identified by visual analysis of traces. The fraction of silent synapses was calculated using an equation: $1-\mathrm{Ln}\left(\mathrm{F}_{-75}\right) / \mathrm{Ln}\left(\mathrm{F}_{+40}\right)$ (Huang et al, 2009).

\section{Data Analysis}

Statistical analyses were performed using GraphPad Prism 5 (GraphPad Software, La Jolla, CA). Differences were tested using the two-tale unpaired or paired $t$-test as indicated and deemed significant with $P<0.05$.

\section{RESULTS}

\section{OF Enhances Avoidance Learning and Activates Neurons in $\mathrm{dmPFC}$ and BLA}

After OF on day 1 , mice were trained and tested in PA on days 2 and 3 (Figure 1a and b). During PA training, control and OF mice showed short latencies of moving in the dark compartment; during testing, each group had longer latency than during training $(P<0.001$; paired $t$-test), and the $\mathrm{OF}$ mice had longer latency than the controls $(P=0.02)$ (Figure 1c), which indicated that OF enhanced PA memory.

Because PA learning in rodents requires interaction between dmPFC and BLA (Malin et al, 2007; Malin and McGaugh, 2006), effect of OF on neuronal activity in these structures was examined by measuring c-Fos immunoreactivity $90 \mathrm{~min}$ after OF. The dmPFC and BLA had more c-Fos-positive cells in OF mice than in controls $(P=0.015)$ (Figure 1d-f), indicating that $\mathrm{OF}$ co-activates dmPFC and BLA and may cause plastic changes in AmPFC-BLA synapses.

\section{OF Alters Glutamatergic Transmission in the Input From dmPFC to BLA}

To study synaptic transmission from dmPFC to BLA, an AAV vector expressing ChR2-YFP fusion protein was injected into dmPFC. Mice underwent OF, followed by slice physiology analysis $24 \mathrm{~h}$ later. Axons from dmPFC expressing ChR2-YFP were stimulated in BLA slice by pulses of blue light, and EPSCs were recorded from putative pyramidal neurons (Morozov et al, 2011) (Figure 2). The relative strength of AMPAR- and NMDAR-mediated transmission was first quantified using the 'AMPAR/NMDAR index', determined as the ratio between the peak response in cell held at $-75 \mathrm{mV}$ membrane potential to the response at $50 \mathrm{~ms}$ after the peak at $+40 \mathrm{mV}$ (Figure $2 \mathrm{~b}$ ). The AMPAR/NMDAR index was lower in OF group than in controls $(P=0.006)$. In contrast, it did not differ from controls after two other forms of aversive exposure, immobilization stress, and auditory fear conditioning. To examine the effect of $\mathrm{OF}$ on a different input to BLA, ChR2-YFP was expressed in the associative sensory area TeA (McDonald, 1998; Morozov et al, 2011). The AMPAR/NMDAR indices did not differ between control and OF groups (Figure $2 \mathrm{~b}$ ). Thus, OF modifies dmPFC-BLA synapses in the behavior-specific and input-specific manner. To further confirm that $\mathrm{OF}$ enhances relative strength of NMDAR-mediated transmission in dmPFC-BLA pathway, the ratio between amplitudes of pharmacologically isolated AMPAR and NMDAR currents was determined. The AMPAR/NMDAR ratio was lower in OF group than in controls (Figure 2c). There was no significant difference between $\mathrm{OF}$ and control groups in reversal potentials of phramacologically isolated currents mediated by AMPAR (control: $-2.0 \pm 2.1 \mathrm{mV}, n=9$ cells per three mice; OF: $-2.3 \pm 1.6 \mathrm{mV}, n=11$ cells per three mice, $P>0.05)$ or NMDAR (control: $2.1 \pm 0.7 \mathrm{mV}, n=12$ cells per three mice; OF: $1.8 \pm 1.2 \mathrm{mV}, n=9$ cells per three mice, $P>0.05$ ) (Figure 2d).

The reduced AMPAR/NMDAR current ratio may result from a decrease in AMPAR current and/or an increase in NMDAR current. Minimal-like stimulation was employed to compare the currents while reducing impact from variability 
of ChR2 expression among slices (Figure 3a-d). To assess presence of multiquantal release during the minimal-like stimulation, AMPAR currents elicited by paired stimuli were recorded from a subset of neurons (eight from control and nine from OF mice). When release is multiquantal, changes in failure rate of response from the first to the second pulse a AAV-ChR2 injection site
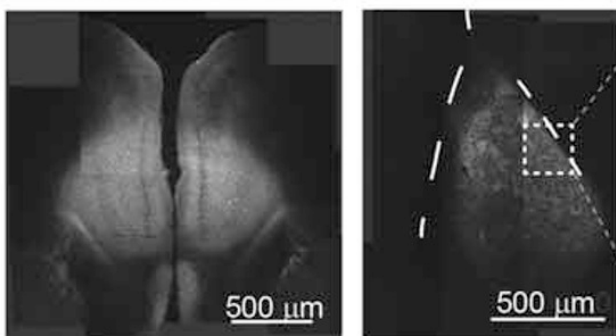

b

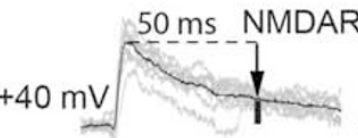

$-75 \mathrm{mV}$

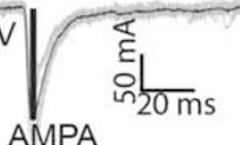

c
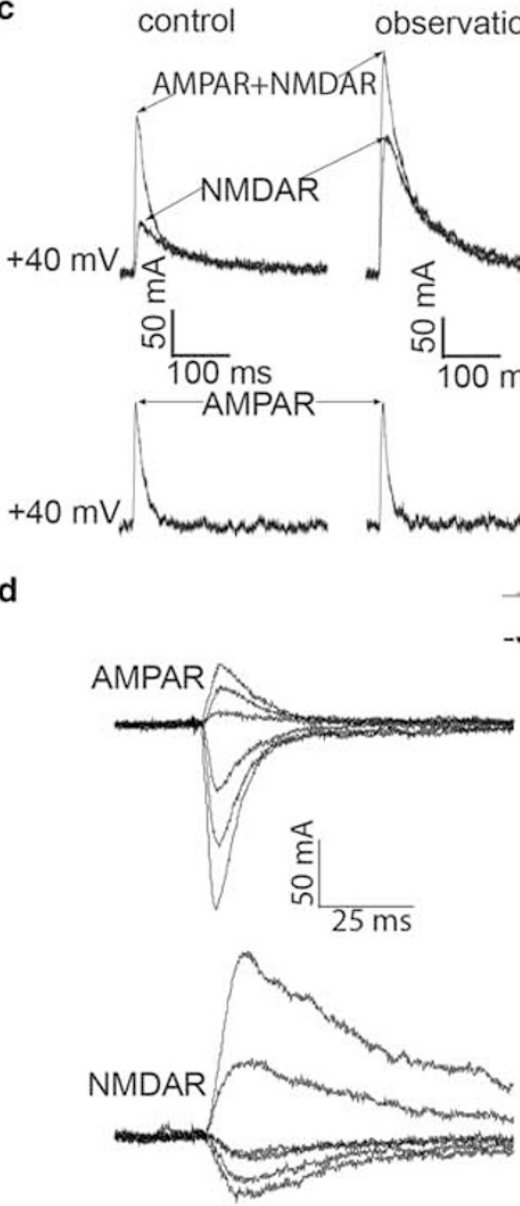

AMPA

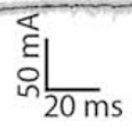

- control fear recording site

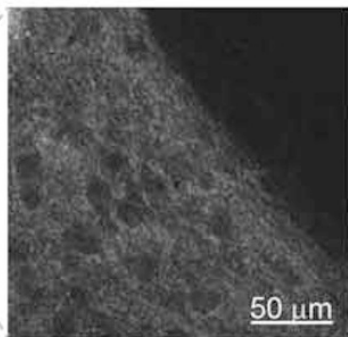

control

observational fear

auditory fear conditioning

口 immobilization stress

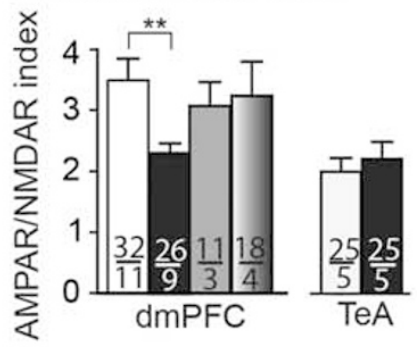

control

observational fear

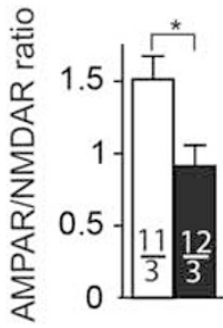

-...observational $0+1.0$
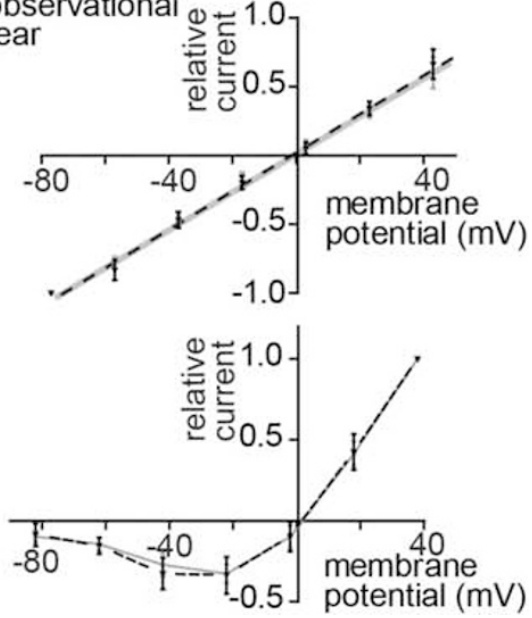
are expected to negatively correlate with changes in response potency (Stevens and Wang, 1994). Despite the failure rate of the second response being higher on average and in majority of cells (13 out of 17) (first: $0.61 \pm 0.05$, second: $0.69 \pm 0.05$, $n=17, P=0.009$, paired $t$-test) (Figure $3 \mathrm{c}$ ), there were no significant differences between potencies of the first and second responses $(P=0.58$, paired $t$-test) (Figure $3 \mathrm{~b}$ and $\mathrm{c}$ ) and no correlations between the ratio of potencies at the first and second stimulation and the ratio of failure rates $\left(R^{2}=0.037\right)$. These results suggest that the proportion of multi-synaptic responses was low. The observed paired-pulse depression was likely caused by presynaptic expression of channelrhodopsin, which has been reported to strongly increase release probability from glutamatergic synapses (Zhang and Oertner, 2007).

The amplitudes of pharmacologically isolated AMPAR EPSCs in OF group did not differ from control, but NMDAR EPSCs amplitudes were higher (Figure 3d). The decay of NMDAR-mediated currents evoked by widefield stimulation was slower in OF group (decay time from 90 to $30 \%$ of peak, $P=0.018$ ) (Figure 3e). However, the sensitivity of pharmacologically isolated NMDAR currents to ifenprodil, a selective antagonist of NMDA receptors containing the NR2B subunit with slower kinetics, did not differ between control and $\mathrm{OF}$ groups (percentage of baseline current amplitude after $10 \mathrm{~min}$ perfusion with $3 \mu \mathrm{M}$ ifenprodil, control: $66 \pm 7 \%, n=5$ cells per 2 mice, OF: $68 \pm 6 \%, n=5$ cells per 2 mice).

\section{OF Generates Silent Synapses in dmPFC Input to BLA}

Lower AMPAR/NMDAR current ratio together with higher amplitude and slower decay of NMDAR current predict presence of silent synapses, which have NMDAR but lack functional AMPAR (Hanse et al, 2013). Silent synapses were examined using the $\mathrm{CV}$ analysis and comparison of failures of NMDAR- and AMPAR-mediated EPSCs evoked by weak stimulation (Kullmann, 1994; Marie et al, 2005; Pan et al, 2009). The CV-NMDAR did not differ from CV-AMPAR in controls ( $n=13$ cells per 7 mice, $P>0.05$, paired $t$-test), but was lower in OF group $(n=11$ cells per 6 mice, $P=0.005)$ and the CV-NMDAR/CV-AMPAR ratio was lower in OF group than in controls $(P=0.046$; Figure $4 \mathrm{a}$ and $\mathrm{b})$. The failure rate of AMPAR EPSC was similar to that of mixed AMPAR+NMDAR EPSCs in control group $(n=17, P>0.05$, paired $t$-test), but higher in OF group $(n=16, P<0.001)$ (Figure $4 \mathrm{c}$ and $\mathrm{d}$ ). Consistently, fraction of silent synapses calculated using the equation $1-\operatorname{Ln}\left(\mathrm{F}_{-75}\right) / \operatorname{Ln}\left(\mathrm{F}_{+40}\right)$ was higher in OF group (Figure 4d).

\section{Sub-Anesthetic Dose of Ketamine Abolishes Effect of OF on Avoidance Learning and Prevents Formation of Silent Synapses}

Evidence that ketamine increases AMPAR over NMDAR function (Maeng et al, 2008; Nosyreva et al, 2013; Tizabi et al, 2012) predicts that ketamine counters the effects from $\mathrm{OF}$. Mice were injected with ketamine $(10 \mathrm{mg} / \mathrm{kg})$ or saline immediately after OF, followed by the PA training on the next day. The saline-injected OF mice had longer latency to enter dark compartment during PA testing than salineinjected controls $(P=0.015)$; in contrast, the latencies did not differ between controls and OF mice in the ketamineinjected group (Figure 5a). The analysis of synaptic transmission in ketamine-injected OF mice showed higher AMPAR/NMDAR index $(P=0.02)$, higher AMPAR/ NMDAR ratio $(P=0.004)$, higher CV NMDAR/CV AMPAR ratio $(P=0.0014)$, and lower fraction of silent synapses $(P=0.012)$, when compared with non-injected OF mice (Figure 5b). In ketamine-injected controls, AMPAR/ NMDAR index, AMPAR/NMDAR ratio, and CV NMDAR/ CV AMPAR ratio did not differ significantly from those in non-injected controls $(P>0.05)$. Thus, ketamine normalized PA learning and synaptic transmission in OF mice, but had no effect in controls.

\section{DISCUSSION}

Our key findings are that the psychological trauma from $\mathrm{OF}$ generates silent synapses in dmPFC-BLA pathway and enhances subsequent PA learning, whereas ketamine prevents both effects.

\section{Psychological Trauma and Fear Memory}

Previous studies have shown that exposure to distressed conspecific in rodents acts as unconditional stimulus (US) in both contextual and cued fear conditioning (Chen et al, 2009; Jeon et al, 2010; Yusufishaq and Rosenkranz, 2013) and enhances active avoidance learning performed in a different context immediately after the exposure (Knapska et al, 2010). Here we found enhanced PA learning $24 \mathrm{~h}$ after OF, which implies lasting modifications of the fear learning circuits. Elevated c-Fos expression in $\mathrm{dmPFC}$ and BLA after OF indicated that modifications may involve the dmPFC-BLA

Figure 2 OF, but not other forms of stress, decreases AMPAR/NMDAR current ratio in dmPFC-BLA synapses (a) Example images of ChR2-Venus AAV injection site and recording site. Left: A tiled fluorescent image of dmPFC. Middle: A tiled confocal image of BLA from the same animal, dotted white lines mark positions of the external capsule (left) and the internal capsule (right). Right: A magnified image of ChR2-Venus expressing fibers within the dotted square. (b) Left: examples of AMPAR (lower) and AMPAR/NMDAR mixed currents (upper) in neurons from a control mouse (left) and an OF mouse (right). Averages of 10 consecutive sweeps (gray) are shown in black. Vertical black bars illustrate reading of each current. Right: AMPAR/NMDAR indices for BLA inputs from dmPFC (left) or TeA (right) in each behavioral group: control (white), OF (black), auditory fear conditioning (gray), and immobilization (gradient). (c) Left: examples of the mixed AMPAR- and NMDAR-mediated currents recorded at $+40 \mathrm{mV}$, NMDAR currents isolated in the presence of $20 \mu \mathrm{M}$ CNQX and AMPAR-traces obtained by digital subtraction of the NMDAR trace from the mixed trace. Right: AMPAR/NMDAR ratios for BLA inputs from dmPFC in control (white) OF (black) groups. (d) Left: examples of pharmacologically isolated EPSCs evoked at holding potentials ranging from -77 to $+43 \mathrm{mV}$ for AMPAR (top) and from -82 to +38 for NMDAR (bottom) at a step of $20 \mathrm{mV}$. Right: averaged current-voltage plots of the AMPAR (top) and NMDAR (bottom) currents in control (gray symbols), and $\mathrm{OF}$ (black symbols) groups. Current values are normalized to those at $-77 \mathrm{mV}$ and $+38 \mathrm{mV}$ membrane potential for AMPAR and NMDAR, respectively. Data are presented as mean \pm SEM. Number of cells (upper) and animals (lower) are shown. *p $<0.05$, *** $p<0.0$ I. BLA, basolateral amygdala; dmPFC, dorsomedial prefrontal cortex; $\bar{O}$, observational fear. 
a

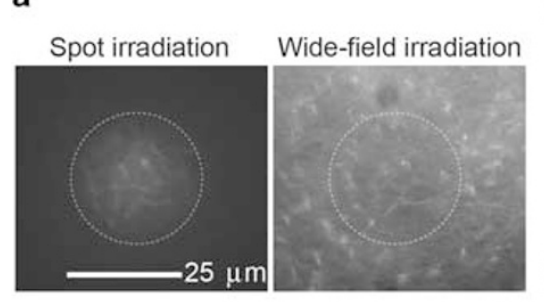

d

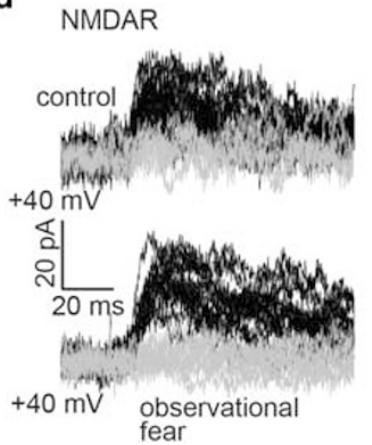

b

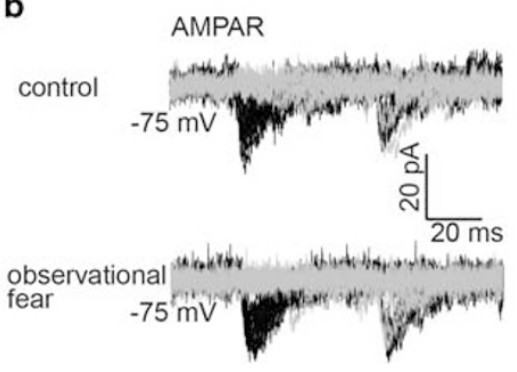

C

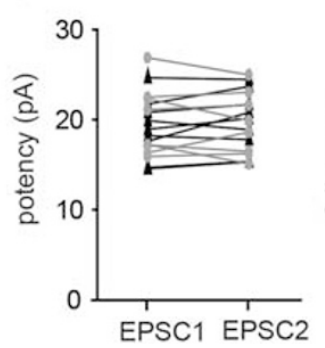

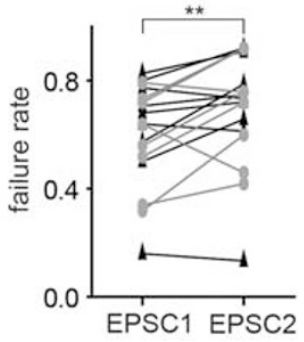

e
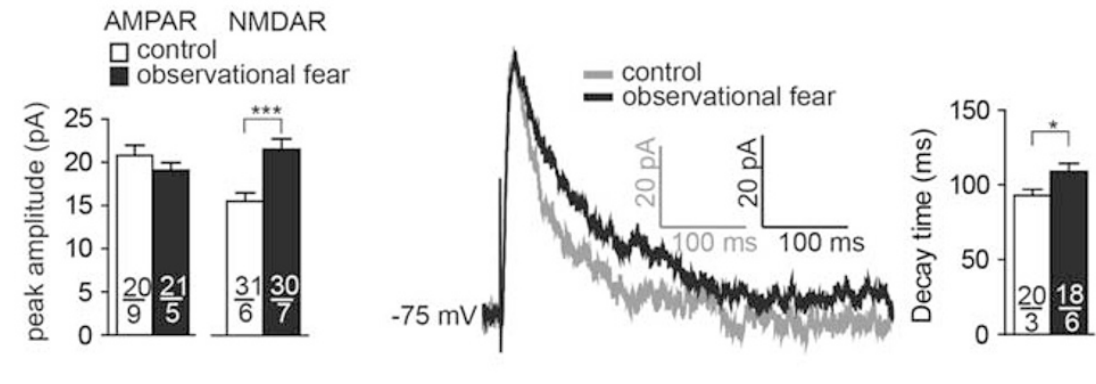

Figure 3 OF alters NMDAR-mediated currents. (a) Fluorescent images of an amygdala slice irradiated with a $25 \mu \mathrm{m}$ spot (left) or a broad beam (right) of blue light. (b) Representative traces (25 per cell) of AMPAR-mediated currents elicited by paired pulses of minimal-like stimulation of dmPFC input to BLA in control (upper) and OF mice (lower). Success EPSC responses to the first pulse are shown in black, failures in gray. (c) Summary diagram of mean potencies (left) and failure rates (right) of synaptic responses in individual cells to paired stimulation in control (gray circles) and OF group (black triangles). (d) Left: representative traces (25 per cell) of NMDAR-mediated currents elicited by single pulses of minimal-like stimulation, marked as in b. Right: summary of peak amplitudes of AMPAR- and NMDAR-mediated currents evoked by minimal-like stimulation. (e) Left: averages of five traces of NMDAR-mediated currents evoked by broad beam stimulation, scaled to illustrate slower NMDAR kinetics after OF. Right: NMDAR-mediated current decay time from 90 to $30 \%$ of the peak. White and black colors represent, respectively, control and OF. Data are presented as mean \pm SEM. Number of cells (upper) and animals (lower) are shown. ${ }^{*} p<0.05$, ** $p<0.01$, **** $p<0.00$ I. BLA, basolateral amygdala; dmPFC, dorsomedial prefrontal cortex; OF, observational fear.

pathway. Given the dmPFC-BLA interactions are required for PA learning (Malin et al, 2007; Malin and McGaugh, 2006) and correlate with fear memory (Lesting et al, 2011; Popa et al, 2010), the formation of new silent synapses is a potential mechanism to enhance PA learning via strengthening dmPFC-BLA connectivity.

\section{Formation and Role of Silent Synapses}

AMPAR silent synapses are abundant during early postnatal development, but by post puberty, they disappear from many areas of the brain (Hanse et al, 2013), including the thalamocortical (Isaac et al, 1997) and thalamo-amygdala pathways (Pan et al, 2009). Recently, new silent synapses were found in the adult brain after exposure to cocaine (Huang et al, 2009; Koya et al, 2012), trauma (Lo et al, 2011), chronic stress (Suvrathan et al, 2014), or during aging (Sametsky et al, 2010). Their formation involves de novo synaptogenesis and (or) removal of AMPAR from regular synapses (Hanse et al, 2013). Our findings suggest that OF recruits new NMDAR without removal of AMPAR, because NMDAR currents increased without significant changes in AMPAR currents. A potential caveat in our experiments is the reliance on the minimal-like stimulation. Despite the analyses of AMPAR responses to the paired minimal-like stimulation suggested that majority of responses resulted from single quanta release, the same analysis was not applied to NMDAR currents because of their slow decay kinetics. Therefore we could not completely rule out multiquantal origin of the
NMDAR responses, leading to a possibility that the higher NMDAR currents in OF group resulted from presynaptic changes. On the other hand, the slower decay of NMDAR current suggests increased proportion of NR2B subunits (Monyer et al, 1994; Yuan et al, 2009), which is an indication of postsynaptic changes in NMDA receptor. However, we did not detect differences in sensitivity of NMDAR currents to the NR2B receptor antagonist ifenprodil, which was consistent with a report that all NMDARs in BLA contain at least one NR2B subunit and are sensitive to the antagonist (Delaney et al, 2012).

While their role in dmPFC-BLA pathway remains unknown, silent synapses are formed in the nucleus accumbens of rats during cocaine self-administration, and are involved in cocaine-induced locomotor sensitization and cocaine craving by allowing incorporation of AMPAR (Brown et al, 2011; Lee et al, 2013; Ma et al, 2014). By the same mechanism, silent synapses may render the dmPFCBLA pathway more prone to facilitation. In addition, they may provide additional calcium influx and enable stronger plasticity in response to aversive stimuli, like footshocks, which depolarize BLA neurons (Crane et al, 2009) and can relieve magnesium block of NMDA receptors.

\section{Ketamine Against Psychological Trauma}

Normalization of AMPAR/NMDAR ratio and elimination of silent synapses by ketamine are consistent with findings that ketamine increases AMPAR/NMDAR ratio and enhances 
a
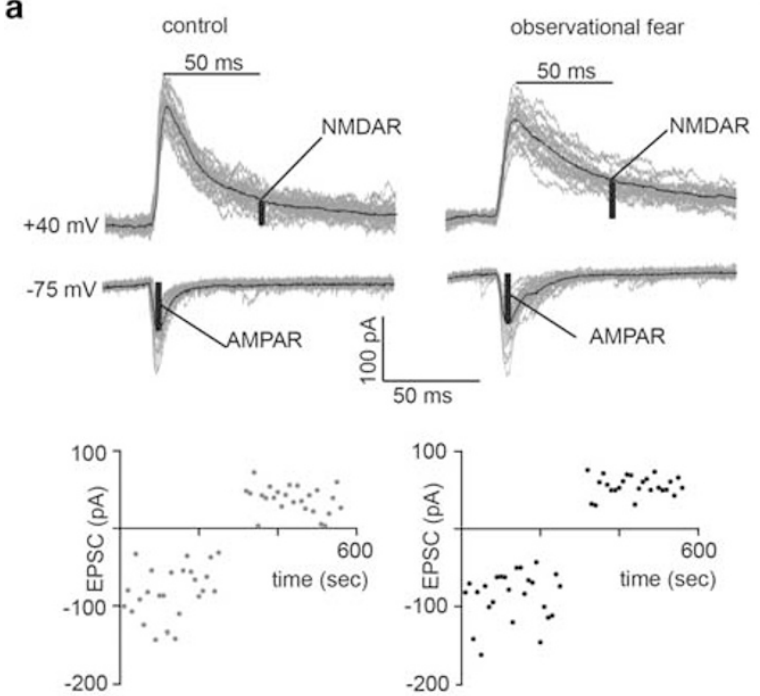

c

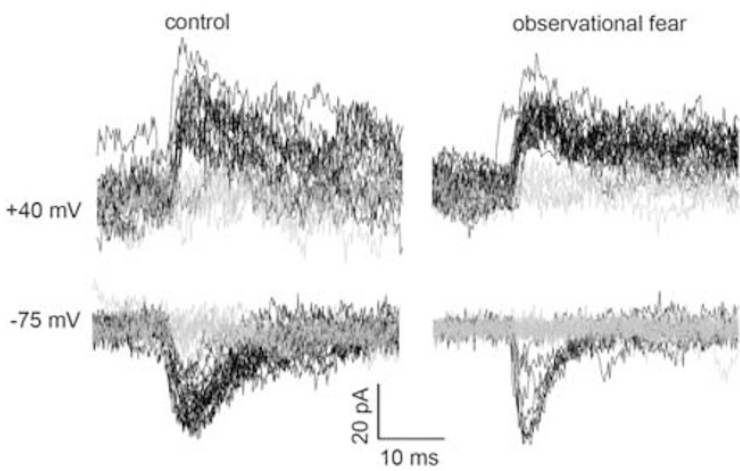

b

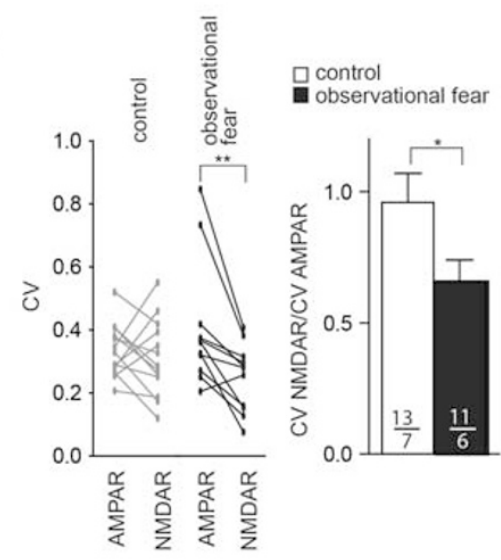

d

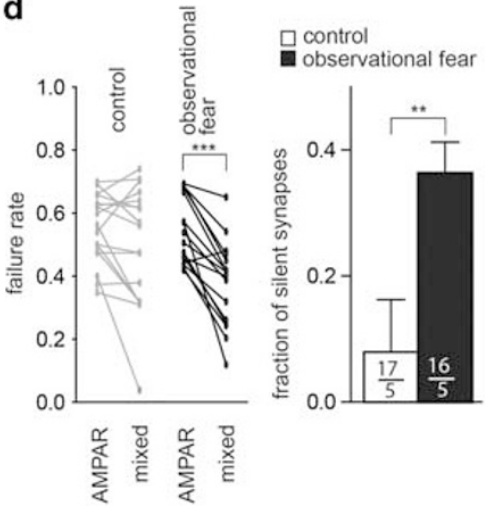

Figure 4 OF generates silent synapses. ( $a$ and b) $C V$ analyses of AMPAR and NMDAR currents. (a) Example traces (upper) at -75 and $+40 \mathrm{mV}$ from control (left) and OF mice (right) and corresponding amplitude plots (lower). Vertical black bars illustrate reading of each current. Black traces represent averages. (b) Summary diagram for CV of AMPAR and NMDAR currents (left) and for the ratio of CV-NMDAR/CV-AMPAR (right). (c and d) Failure rate test for silent synapses using minimal-like stimulation. (c) Example traces at -75 (lower) and $+40 \mathrm{mV}$ (upper) from control (left) and OF mice (right). Successes EPSC responses and failures are shown, respectively, in black and gray. (d) Failure rates of AMPAR and AMPAR-NMDAR mixed currents and estimated fraction of silent synapses. White/gray and black colors represent, respectively, control and OF. Data are presented as mean \pm SEM. Number of cells (upper) and animals (lower) are shown. $*$ p $<0.05, * * * 0.01$, $* * * * 0<0.001$.

surface expression of AMPAR (Maeng et al, 2008; Nosyreva et al, 2013; Tizabi et al, 2012). However, we did not detect increases in AMPAR/NMDAR in control mice injected with ketamine. The reason for the discrepancy could be the timing of our measures. The reported increases were detected within minutes after single ketamine injection (Maeng et al, 2008; Nosyreva et al, 2013) or after 10 days of repeated injections (Tizabi et al, 2012), whereas our recordings were done $24 \mathrm{~h}$ after injection.

While the network process leading to the formation of silent synapses after OF remains to be determined, a desynchronized neuronal activity has been shown to increase the number of AMPAR-silent synapses (Huupponen et al, 2013). Conversely, correlated pre- and post-synaptic activity causes synaptic unsilencing (Durand et al, 1996; Isaac et al, 1995; Liao et al, 1995). Synchronization of neuronal activity is a plausible mechanism for the effects of ketamine, which induces glutamate outflow and gamma oscillations in human and rodent brain (Hong et al, 2010; Nicolas et al, 2011; Pinault, 2008). Such oscillations may override the specific activity pattern required for silent synapse formation, or unsilence already formed silent synapses. Identification of neuronal activity patterns during $\mathrm{OF}$ and on ketamine treatment in vivo will inform about these possibilities. The prevention of enhanced avoidance learning by ketamine could be achieved either by reversal of changes from OF or by general anterograde attenuation of fear learning. The latter scenario, however was ruled out, because ketamine did not impair avoidance learning in control mice.

Studies of humans revealed enhanced functional connectivity between the anterior cingulate cortex and right amygdala in PTSD (Lanius et al, 2010) and within the default mode network in depression (Scheidegger et al, 2012). Antidepressant doses of ketamine decreased the default mode connectivity (Scheidegger et al, 2012) and reduced core symptoms of PTSD, including avoidance (Feder et al, 2014). Based on these observations in humans and our findings in mice, we hypothesize that silent synapses underlie the enhanced functional connectivity in mental disease, whereas positive effects of ketamine result from their elimination. 

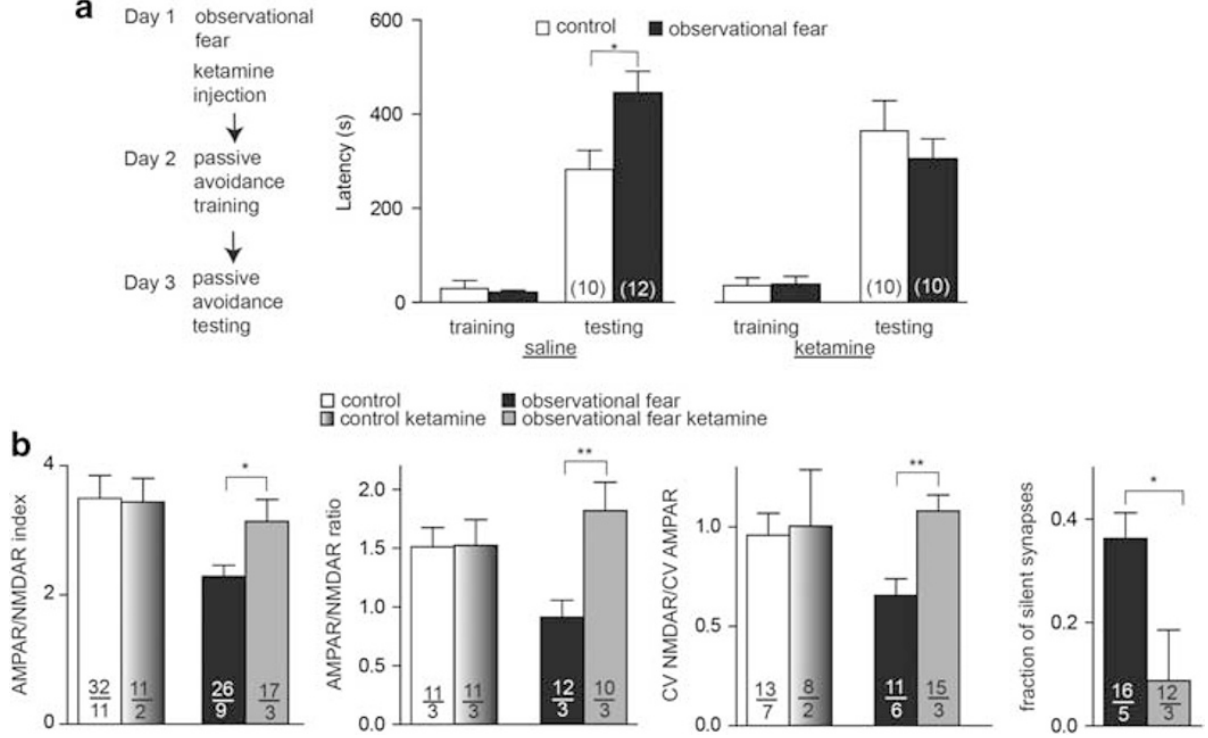

Figure 5 Ketamine prevents effects of OF on PA learning and formation of silent synapses (a) Timeline of experiment (left). Latency to enter dark compartment during PA training and testing in mice injected with saline (middle) or ketamine (right) immediately after OF. (b) AMPAR/NMDAR index (left), AMPAR/NMDAR ratio (left middle), the ratio of CV-NMDAR/CV-AMPAR (right middle) and estimated fraction of silent synapses (right). Data from Figures 2 and 4 are included for comparison. White, black, gradient and gray represent, respectively, control, OF, ketamine-injected controls, and ketamine-injected $O F$ mice. Data are presented as mean \pm SEM. Number of cells (upper) and animals (lower) are shown. $* p<0.05, * * 0.01$.

\section{FUNDING AND DISCLOSURE}

The study has been supported by the Virginia Tech Carilion Research Institute. The authors declare no competing financial interests

\section{REFERENCES}

Amano T, Unal CT, Pare D (2010). Synaptic correlates of fear extinction in the amygdala. Nat Neurosci 13: 489-494.

Brown TE, Lee BR, Mu P, Ferguson D, Dietz D, Ohnishi YN et al (2011). A silent synapse-based mechanism for cocaine-induced locomotor sensitization. J Neurosci 31: 8163-8174.

Chen Q, Panksepp JB, Lahvis GP (2009). Empathy is moderated by genetic background in mice. PloS One 4: e4387.

Cho JH, Deisseroth K, Bolshakov VY (2013). Synaptic encoding of fear extinction in mPFC-amygdala circuits. Neuron 80: 1491-1507.

Church RM (1959). Emotional reactions of rats to the pain of others. J Comp Physiol Psychol 52: 132-134.

Cougle JR, Resnick H, Kilpatrick DG (2009). Does prior exposure to interpersonal violence increase risk of PTSD following subsequent exposure? Behav Res Ther 47: 1012-1017.

Crane JW, Windels F, Sah P (2009). Oscillations in the basolateral amygdala: aversive stimulation is state dependent and resets the oscillatory phase. J Neurophysiol 102: 1379-1387.

Daw MI, Tricoire L, Erdelyi F, Szabo G, McBain CJ (2009). Asynchronous transmitter release from cholecystokinincontaining inhibitory interneurons is widespread and target-cell independent. J Neurosci 29: 11112-11122.

Delaney AJ, Sedlak PL, Autuori E, Power JM, Sah P (2012). Synaptic NMDA receptors in basolateral amygdala principal neurons are triheteromeric proteins: physiological role of GluN2B subunits. J Neurophysiol 109: 1391-1402.

Durand GM, Kovalchuk Y, Konnerth A (1996). Long-term potentiation and functional synapse induction in developing hippocampus. Nature 381: 71-75.

El-Ghundi M, O'Dowd BF, George SR (2001). Prolonged fear responses in mice lacking dopamine D1 receptor. Brain Res 892: 86-93.
Eriksson CB, Vende Kemp H, Gorsuch R, Hoke S, Foy DW (2001). Trauma exposure and PTSD symptoms in international relief and development personnel. J Trauma Stress 14: 205-212.

Feder A, Parides MK, Murrough JW, Perez AM, Morgan JE, Saxena S et al (2014). Efficacy of intravenous ketamine for treatment of chronic posttraumatic stress disorder: a randomized clinical trial. JAMA Psychiatry 71: 681-688.

Figley C (1995). Compassion Fatigue: coping with Secondary Traumatic Stress Disorder in Those Who Treat the Traumatized, Brunner/Mazel: New York.

Gilmartin MR, Balderston NL, Helmstetter FJ (2014). Prefrontal cortical regulation of fear learning. Trends Neurosci 37: 455-464.

Hanse E, Seth H, Riebe I (2013). AMPA-silent synapses in brain development and pathology. Nat Rev Neurosci 14: 839-850.

Hong LE, Summerfelt A, Buchanan RW, O'Donnell P, Thaker GK, Weiler MA et al (2010). Gamma and delta neural oscillations and association with clinical symptoms under subanesthetic ketamine. Neuropsychopharmacology 35: 632-640.

Huang YH, Lin Y, Mu P, Lee BR, Brown TE, Wayman G et al (2009). In vivo cocaine experience generates silent synapses. Neuron 63: 40-47.

Hubner C, Bosch D, Gall A, Luthi A, Ehrlich I (2014). Ex vivo dissection of optogenetically activated mPFC and hippocampal inputs to neurons in the basolateral amygdala: implications for fear and emotional memory. Front Behav Neurosci 8: 64.

Huupponen J, Molchanova SM, Lauri SE, Taira T (2013). Ongoing intrinsic synchronous activity is required for the functional maturation of CA3-CA1 glutamatergic synapses. Cereb Cortex 23: 2754-2764.

Isaac JT, Crair MC, Nicoll RA, Malenka RC (1997). Silent synapses during development of thalamocortical inputs. Neuron 18: 269-280.

Isaac JT, Nicoll RA, Malenka RC (1995). Evidence for silent synapses: implications for the expression of LTP. Neuron 15: 427-434.

Ito W, Pan BX, Yang C, Thakur S, Morozov A (2009). Enhanced generalization of auditory conditioned fear in juvenile mice. Learn Mem 16: 187-192.

Jeon D, Kim S, Chetana M, Jo D, Ruley HE, Lin SY et al (2010). Observational fear learning involves affective pain system and Cav1.2 Ca2+ channels in ACC. Nat Neurosci 13: 482-488. 
Knapska E, Mikosz M, Werka T, Maren S (2010). Social modulation of learning in rats. Learn Mem 17: 35-42.

Koya E, Cruz FC, Ator R, Golden SA, Hoffman AF, Lupica CR et al (2012). Silent synapses in selectively activated nucleus accumbens neurons following cocaine sensitization. Nat Neurosci 15: $1556-1562$.

Kullmann DM (1994). Amplitude fluctuations of dual-component EPSCs in hippocampal pyramidal cells: implications for longterm potentiation. Neuron 12: 1111-1120.

Lanius RA, Bluhm RL, Coupland NJ, Hegadoren KM, Rowe B, Theberge J et al (2010). Default mode network connectivity as a predictor of post-traumatic stress disorder symptom severity in acutely traumatized subjects. Acta Psychiatr Scand 121: 33-40.

Lee BR, Ma YY, Huang YH, Wang X, Otaka M, Ishikawa M et al (2013). Maturation of silent synapses in amygdala-accumbens projection contributes to incubation of cocaine craving. Nat Neurosci 16: 1644-1651.

Lesting J, Narayanan RT, Kluge C, Sangha S, Seidenbecher T, Pape HC (2011). Patterns of coupled theta activity in amygdalahippocampal-prefrontal cortical circuits during fear extinction. PloS One 6: e21714.

Liao D, Hessler NA, Malinow R (1995). Activation of postsynaptically silent synapses during pairing-induced LTP in CA1 region of hippocampal slice. Nature 375: 400-404.

Likhtik E, Stujenske JM, Topiwala MA, Harris AZ, Gordon JA (2014). Prefrontal entrainment of amygdala activity signals safety in learned fear and innate anxiety. Nat Neurosci 17: 106-113.

Lo FS, Zhao S, Erzurumlu RS (2011). Astrocytes promote peripheral nerve injury-induced reactive synaptogenesis in the neonatal CNS. J Neurophysiol 106: 2876-2887.

Ma YY, Lee BR, Wang X, Guo C, Liu L, Cui R et al (2014). Bidirectional modulation of incubation of cocaine craving by silent synapse-based remodeling of prefrontal cortex to accumbens projections. Neuron 83: 1453-1467.

Maeng S, Zarate CA Jr, Du J, Schloesser RJ, McCammon J, Chen G et al (2008). Cellular mechanisms underlying the antidepressant effects of ketamine: role of alpha-amino-3-hydroxy-5-methylisoxazole-4-propionic acid receptors. Biol Psychiatry 63: 349-352.

Malin EL, Ibrahim DY, Tu JW, McGaugh JL (2007). Involvement of the rostral anterior cingulate cortex in consolidation of inhibitory avoidance memory: interaction with the basolateral amygdala. Neurobiol Learn Mem 87: 295-302.

Malin EL, McGaugh JL (2006). Differential involvement of the hippocampus, anterior cingulate cortex, and basolateral amygdala in memory for context and footshock. Proc Natl Acad Sci USA 103: 1959-1963.

Marek R, Strobel C, Bredy TW, Sah P (2013). The amygdala and medial prefrontal cortex: partners in the fear circuit. J Physiol 591 (Pt 10): 2381-2391.

Marie H, Morishita W, Yu X, Calakos N, Malenka RC (2005). Generation of silent synapses by acute in vivo expression of CaMKIV and CREB. Neuron 45: 741-752.

McDonald AJ (1982). Neurons of the lateral and basolateral amygdaloid nuclei: a Golgi study in the rat. J Comp Neurol 212: 293-312.

McDonald AJ (1998). Cortical pathways to the mammalian amygdala. Prog Neurobiol 55: 257-332.

Monyer H, Burnashev N, Laurie DJ, Sakmann B, Seeburg PH (1994). Developmental and regional expression in the rat brain and functional properties of four NMDA receptors. Neuron 12: 529-540.

Morozov A, Sukato D, Ito W (2011). Selective suppression of plasticity in amygdala inputs from temporal association cortex by the external capsule. J Neurosci 31: 339-345.
Munroe JF (1999). Ethical issues associated with secondary trauma in therapists. In: Stamm BH (ed) Secondary Traumatic Stress: SelfCare Issues for Clinicians, Researchers, \& Educators. The Sidran Press: Lutherville, MD, USA. pp 211-229.

Nicolas MJ, Lopez-Azcarate J, Valencia M, Alegre M, Perez-Alcazar M, Iriarte J et al (2011). Ketamine-induced oscillations in the motor circuit of the rat basal ganglia. PloS One 6: e21814.

Nosyreva E, Szabla K, Autry AE, Ryazanov AG, Monteggia LM, Kavalali ET (2013). Acute suppression of spontaneous neurotransmission drives synaptic potentiation. J Neurosci 33: 6990-7002.

Olsson A, Nearing KI, Phelps EA (2007). Learning fears by observing others: the neural systems of social fear transmission. Soc Cogn Affect Neurosci 2: 3-11.

Pan BX, Ito W, Morozov A (2009). Divergence between thalamic and cortical inputs to lateral amygdala during juvenile-adult transition in mice. Biol Psychiatry 66: 964-971.

Petreanu L, Mao T, Sternson SM, Svoboda K (2009). The subcellular organization of neocortical excitatory connections. Nature 457: $1142-1145$

Pinault D (2008). N-methyl d-aspartate receptor antagonists ketamine and MK-801 induce wake-related aberrant gamma oscillations in the rat neocortex. Biol Psychiatry 63: 730-735.

Popa D, Duvarci S, Popescu AT, Lena C, Pare D (2010). Coherent amygdalocortical theta promotes fear memory consolidation during paradoxical sleep. Proc Natl Acad Sci USA 107: 6516-6519.

Resnick HS, Yehuda R, Pitman RK, Foy DW (1995). Effect of previous trauma on acute plasma cortisol level following rape. Am J Psychiatry 152: 1675-1677.

Sametsky EA, Disterhoft JF, Geinisman Y, Nicholson DA (2010). Synaptic strength and postsynaptically silent synapses through advanced aging in rat hippocampal CA1 pyramidal neurons. Neurobiol Aging 31: 813-825.

Scheidegger M, Walter M, Lehmann M, Metzger C, Grimm S, Boeker $\mathrm{H}$ et al (2012). Ketamine decreases resting state functional network connectivity in healthy subjects: implications for antidepressant drug action. PloS One 7: e44799.

Senn V, Wolff SB, Herry C, Grenier F, Ehrlich I, Grundemann J et al (2014). Long-range connectivity defines behavioral specificity of amygdala neurons. Neuron 81: 428-437.

Stevens CF, Wang Y (1994). Changes in reliability of synaptic function as a mechanism for plasticity. Nature 371: 704-707.

Stujenske JM, Likhtik E, Topiwala MA, Gordon JA (2014). Fear and safety engage competing patterns of theta-gamma coupling in the basolateral amygdala. Neuron 83: 919-933.

Suvrathan A, Bennur S, Ghosh S, Tomar A, Anilkumar S, Chattarji S (2014). Stress enhances fear by forming new synapses with greater capacity for long-term potentiation in the amygdala. Philos Trans R Soc Lond B Biol Sci 369: 20130151.

Tizabi Y, Bhatti BH, Manaye KF, Das JR, Akinfiresoye L (2012). Antidepressant-like effects of low ketamine dose is associated with increased hippocampal AMPA/NMDA receptor density ratio in female Wistar-Kyoto rats. Neuroscience 213: 72-80.

Warren BL, Vialou VF, Iniguez SD, Alcantara LF, Wright KN, Feng J et al (2013). Neurobiological sequelae of witnessing stressful events in adult mice. Biol Psychiatry 73: 7-14.

Yuan H, Hansen KB, Vance KM, Ogden KK, Traynelis SF (2009). Control of NMDA receptor function by the NR2 subunit aminoterminal domain. J Neurosci 29: 12045-12058.

Yusufishaq S, Rosenkranz JA (2013). Post-weaning social isolation impairs observational fear conditioning. Behav Brain Res 242: 142-149.

Zhang YP, Oertner TG (2007). Optical induction of synaptic plasticity using a light-sensitive channel. Nat Methods 4: 139-141. 